\title{
KAJIAN NILAI-NILAI SOSIAL DAN BUDAYA \\ PADA KAKAWIHAN KAULINAN BARUDAK LEMBUR SERTA IMPLEMENTASINYA DALAM PEMBELAJARAN BAHASA DAN SASTRA INDONESIA BERBASIS MULTIKULTURAL
}

\author{
Yusida Gloriani \\ FKIP Universitas Kuningan \\ Pos-el: glorianiyusida@yahoo.com
}

\begin{abstract}
Abstrak
Indonesia adalah sebuah negara yang memiliki kekayaan dan keanekaragaman budaya. Setiap suku bangsa di Indonesia memiliki ciri khas budayanya masing-masing. Kekayaan budaya ini harus dipertahankan dan dilestarikan, karena budaya itu merupakan pribadi asli bangsa Indonesia. Folklor Indonesia merupakan salah satu jenis tradisi lokal yang berkembang pada masyarakat Indonesia. Folklor merupakan salah satu bentuk kekayaan kebudayaan Indonesia yang berkembang sejak zaman dahulu. "Folklore is a way of understanding people and the wide-ranging creative ways we express who are and what we value and believe" (Sims, 2005: xi). Kakawihan merupakan salah satu bentuk folklor lisan hasil kebudayaan lama masyarakat Sunda. Kakawihan ini sering dikaitkan dengan "kaulinan barudak urang Sunda", artinya bahwa kakawihan tidak terlepas dari sebuah nyanyian yang sering dibawakan pada permainan anak-anak masyarakat Sunda. Kakawihan sebagai sebuah kebudayaan lokal masyarakat Sunda yang harus dijaga kelestariannya, memunculkan sebuah kearifan lokal (local wisdom) yang harus menjadi sebuah kekayaan dan khazanah kebudayaan Indonesia. Upaya untuk menjaga, memelihara, membina, dan menumbuhkembangkan kebudayaan lokal yang ada, diantaranya pemerintah melaksanakan pendidikan multikultural. Penelitian ini difokuskan pada pengkajian secara etnopedagogis tentang kakawihan kaulinan barudak lembur dengan cara mengkaji nilai-nilai sosial dan nilai-nilai budaya yang terdapat di dalamnya. Sebagai bentuk pelestariannya, hasil penelitian ini akan diimplementasikan dalam pendidikan bahasa dan sastra Indonesia yang berbasis multikultural.
\end{abstract}

Kata kunci: folklor, kakawihan kaulinan barudak lembur, nilai-nilai sosial, nilai-nilai budaya, etnopedagogi dan pendidikan multikultural

\section{THE EXAMINATION OF CULTURAL AND SOCIAL VALUES OF KAKAWIHAN KAULINAN BARUDAK LEMBUR AND THEIR IMPLEMENTATION IN THE MULTICULTURAL TEACHING OF INDONESIAN LANGUAGE AND LITERATURE}

\begin{abstract}
Indonesia is a nation with a rich variety of culture. Each ethnic group in this country has distinct characteristics. This cultural richness has to be preserved, for culture is Indonesian inherent characteristic. Indonesia's folklore is a form of local tradition that develops among the Indonesian society. It is part of Indonesian cultural richness, which has developed for ages. Folklore is a way of understanding people and the wide-ranging creative ways we express who are and what we value and believe" (Sims, 2005: xi). Kakawihan (Sundanese songs) is a sort of oral folklore that stems from old Sundanese culture. It is often associated with "kaulinan barudak urang Sunda" (the game of Sundanese children), meaning that kakawihan is inseparable from songs in the game of Sundanese children. Kakawihan as part
\end{abstract}


of local culture of Sunda has to be preserved, since it gives rise to local wisdom that has been inherent part of the richness of Indonesian culture. Among the ways of preserving and cultivating local culture is multicultural education. This research focuses on an etnopedagogical examination of kakawihan kaulinan barudak lembur by investigating their cultural and social values. As a form of preservation measure, the results of the research will be implemented through the multicultural teaching of Indonesian language and culture.

Key words: folklore, Kakawihan Kaulinan Barudak Lembur, social values, cultural values, etnopedagogical and multicultural education

\section{PENDAHULUAN}

Penelitian ini dilatarbelakangi oleh fenomena tentang keanekaragaman etnik, agama, dan budaya masyarakat Indonesia yang menimbulkan berbagai konflik. Penyebab timbulnya konflik ini diantaranya karena keegoisan, ketidakpedulian, perasaan yang selalu menganggap dirinya atau kelompoknya yang paling benar. Hilangnya jati diri bangsa ini di antaranya dipengaruhi pesatnya kemajuan teknologi komunikasi dan teknologi informasi tanpa filter, juga kuatnya pengaruh-pengaruh budaya asing dan cara berpikir yang berbeda dalam memaknai kehidupan.

Penanaman terhadap pengakuan keragaman etnis dan budaya masyarakat Indonesia merupakan upaya merespons fenomena konflik etnis dan sosial-budaya yang muncul di tengah-tengah masyarakat. Penanaman kembali nilai-nilai karakter yang terkandung dalam warisan budaya bangsa, diantaranya penanaman nilai-nilai sosial dan budaya melalui kakawihan kaulinan barudak lembur akan membantu membentuk kembali beberapa karakter bangsa yang hilang.

Kakawihan merupakan salah satu bentuk folklor lisan hasil kebudayaan lama masyarakat Sunda. Kakawihan didendangkan dalam permainan anak-anak masyarakat Sunda. Saat mendendangkan kakawihan, anak-anak akan merasakan kesenangan atau kegembiraan, berbagi suka, saling berbagi perasaan, berkomunikasi, dan berinteraksi dengan teman-temannya. Namun di balik permainan itu, kakawihan pun digunakan untuk menyampaikan sebuah maksud dengan menggunakan bahasa sandi atau simbol bahasa yang hanya dimengerti oleh kelompoknya dan sulit untuk dipahami oleh orang lain di luar komunitasnya. Untuk memahami kakawihan sebagai salah satu warisan budaya Sunda, dibutuhkan pemahaman tentang folklor, selain itu, dibutuhkan juga pengetahuan yang mendalam tentang nilainilai sosial dan budaya masyarakat Sunda. Sekarang, kakawihan ini sudah mulai dilupakan, bahkan tidak pernah lagi terdengar didendangkan saat bermain oleh anak-anak pada masyarakat Sunda.

Pelaksanaan pendidikan berbasis multikultural di Indonesia didasari oleh Undang-Undang No. 20 Tahun 2003 tentang Sistem Pendidikan Nasional pasal 4, yang berbunyi

"Pendidikan dilaksanakan secara
demokratis, tidak diskriminatif dengan
menjunjung tinggi Hak Asasi Manusia
(HAM), nilai keagamaan, nilai kultural
dan kemajemukan bangsa" Depdiknas.
(2003).

Ide pendidikan multikultural telah menjadi komitmen global yang direkomendasi oleh UNESCO pada tahun 1994 di Jenewa. Rekomendasi itu di antaranya memuat empat pesan. Pertama, pendidikan hendaknya mengembangkan kemampuan untuk mengakui dan menerima nilai-nilai yang ada dalam kebhinnekaan pribadi, jenis kelamin, masyarakat dan budaya serta mengembangkan kemampuan untuk berkomunikasi, berbagi dan bekerja sama dengan yang lain. Kedua, pendidikan hendaknya meneguhkan jati diri dan mendorong konvergensi gagasan dan 
penyelesaian-penyelesaian

yang

memperkokoh perdamaian, persaudaraan dan solidaritas antara pribadi dan masyarakat. Ketiga, pendidikan hendaknya meningkatkan kemampuan menyelesaikan konflik secara damai dan tanpa kekerasan. Karena itu, keempat pendidikan hendaknya juga meningkatkan pengembangan kedamaian dalam diri pikiran peserta didik sehingga dengan demikian mereka mampu membangun secara lebih kokoh kualitas toleransi, kesabaran, kemauan untuk berbagi dan memelihara (Risal, 2011).

Berdasarkan hal tersebut di atas, maka pelaksanaan pendidikan yang berbasis budaya lokal, salah satunya kakawihan kaulinan budak lembur merupakan salah satu bentuk implementasi dari pendidikan multikultural ini. Pendidikan multikultural ini tidak lepas dari proses pembudayaan pada masyarakat belajar. Penanaman terhadap pengakuan keragaman etnis dan budaya masyarakat Indonesia merupakan upaya merespons fenomena konflik etnis dan sosial-budaya yang muncul di tengahtengah masyarakat. Penanaman kembali nilai-nilai karakter yang terkandung dalam warisan budaya bangsa, di antaranya penanaman nilai-nilai sosial dan budaya pada kakawihan ini akan membantu membentuk kembali beberapa karakter yang hilang.

Pengkajian pada kakawihan kaulinan budak lembur sebagai salah satu bentuk folklor lisan akan menumbuhkan kenikmatan estetis dan kenikmatan intelektual sehingga akan menumbuhkan kematangan emosional dan kematangan intelektual. Folklor bercerita dan mengungkapkan tentang warna-warna kehidupan serta ekspresi masyarakat zaman dahulu. Pada folklor, akan diperoleh pula pandangan-pandangan filosofis tentang kehidupan dan bagaimana menjalani kehidupan.

\section{METODE}

Metode penelitian yang penulis gunakan adalah metode analisis deskriptif kualitatif. Sesuai dengan masalah dan tujuan penelitian di atas, bahwa penelitian ini menggambarkan hasil kajian secara etnopedagogik nilai-nilai sosial dan nilainilai budaya lokal pada kakawihan kaulinan barudak lembur yang ada di Kabupaten Kuningan.

\section{HASIL DAN PEMBAHASAN Folklor}

Folklor sering diidentikkan dengan tradisi dan kesenian yang berkembang pada zaman sejarah dan telah menyatu dalam kehidupan masyarakat. Di dalam masyarakat Indonesia, setiap daerah, kelompok, etnis, suku bangsa, golongan, agama, masing-masing telah mengembangkan folklornya sendiri-sendiri sehingga di Indonesia terdapat aneka ragam folklor. Menurut Danandjaja (1991: 1) folklor ialah kebudayaan manusia (kolektif) yang diwariskan secara turun-temurun, baik dalam bentuk lisan maupun gerak isyarat. Dapat juga diartikan Folklor adalah adatistiadat tradisonal dan cerita rakyat yang diwariskan secara turun-temurun, dan tidak dibukukan, merupakan kebudayaan kolektif yang tersebar dan diwariskan turun menurun.

Mempelajari folklor merupakan sebuah langkah untuk memahami dan mempelajari kehidupan sehari-hari masyarakat zaman dahulu dalam berkomunikasi, berinteraksi, dan berekspresi, juga dalam berseni. Hasil seni mereka dalam mengekspresikan diri dan berkomunikasi itu dapat berupa folksong (nyanyian rakyat), folk specch (cerita rakyat), atau berupa artefak-artefak. Menurut Sims (2005: 3) "Studying folklore is a way of learning about people, of thinking about how we communicate and make meaning".

Kata folklor merupakan pengIndonesiaan dari bahasa Inggris. Kata tersebut merupakan kata majemuk yang berasal dari dua kata dasar yaitu folk dan lore. 
Pengertian folklor adalah bagian dari kebudayaan yang disebarkan dan diwariskan secara tradisional, baik dalam bentuk lisan maupun contoh yang disertai dengan gerak isyarat atau alat pembantu pengingat.

Agar dapat membedakan antara folklor dengan kebudayaan lainnya, harus diketahui ciri-ciri utama folklor. Folklor memiliki ciri-ciri sebagai berikut.

1) Penyebaran dan pewarisannya biasanya dilakukan secara lisan, yaitu melalui tutur kata dari mulut ke mulut dari satu generasi ke generasi selanjutnya.

2) Bersifat tradisional, yaitu disebarkan dalam bentuk relatif tetap atau dalam bentuk standar.

3) Berkembang dalam versi yang berbedabeda. Hal ini disebabkan penyebarannya secara lisan sehingga folklor mudah mengalami perubahan. Akan tetapi, bentuk dasarnya tetap bertahan.

4) Bersifat anonim, artinya pembuatnya sudah tidak diketahui lagi orangnya.

5) Biasanya mempunyai bentuk berpola Kata-kata pembukanya misalnya. Menurut sahibil hikayat (menurut yang empunya cerita) atau dalam bahasa Jawa misalnya dimulai dengan kalimat anuju sawijing dina (pada suatu hari).

6) Mempunyai manfaat dalam kehidupan kolektif. Cerita rakyat misalnya berguna sebagai alat pendidikan, pelipur lara, protes sosial, dan cerminan keinginan terpendam.

7) Bersifat pralogis, yaitu mempunyai logika sendiri yang tidak sesuai dengan logika umum. Ciri ini terutama berlaku bagi folklor lisan dan sebagian lisan.

8) Menjadi milik bersama (colective) dari masyarakat tertentu.

9) Pada umumnya bersifat lugu atau polos sehingga seringkali kelihatannya kasar atau terlalu sopan. Hal itu disebabkan banyak folklor merupakan proyeksi (cerminan) emosi manusia yang jujur (Danandjaja, 1991: 3-4).

Jan Harold Brunvand (dalam Danandjaja, 1991: 21) mengelompokkan folklor dalam tiga kelompor besar berdasarkan tipenya: (1) folklor lisan (verbal folklore), (2) folklor sebagian lisan (partly verbal folklore), (3) folklor bukan lisan (nonverbal folklore), atau masingmasing istilahnya mentifacts, sociofacts, dan artifacts.

Folklor lisan adalah folklor yang bentuknya murni lisan. Yang termasuk dalam kelompok ini adalah: (a) bahasa rakyat (folk specch) seperti logat, julukan, pangkat tradisional, titel kebangsawanan; (b) ungkapan tradisional, seperti peribahasa, pepatah dan pemeo; (c) pertanyaan tradisional seperti teka-teki; (d) puisi rakyat, seperti pantun, gurindam, syair; (e) cerita prosa rakyat, seperti mite, legenda, dan dongeng; dan (f) nyanyian rakyat.

Folklor sebagian lisan adalah folklor yang bentuknya merupakan campuran unsur lisan dan bukan lisan, misalnya kepercayaan rakyat, permainan rakyat, teater rakyat, tari rakyat, adat istiadat, upacara, pesta rakyat.

Folklor bukan lisan adalah folklor yang bentuknya bukan lisan, misalnya yang material, arsitektur rakyat (bentuk rumah, lumbung padi), kerajinan tangan rakyat, pakaian adat, perhiasan, makanan dan minuman rakyat, obat-obatan tradisional. Yang bukan material misalnya gerak isyarat tradisional (gesture), bunyi isyarat untuk komunikasi rakyat (kentongan tanda bahaya, bunyi gendang), dan musik rakyat.

Jika dilihat berdasarkan tipenya tersebut, maka kakawihan kaulinan barudak lembur termasuk pada folklor lisan yang berbentuk nyanyian rakyat, karena kakawihan ini sering dinyanyikan masyarakat Sunda terutama anak-anak pada saat mereka bermain dengan temantemannya.

\section{Kakawihan}

Kakawihan barudak lembur atau kawih murangkalih yaitu kawih yang biasa dilantunkan atau didendangkan oleh anakanak, baik itu di dalam rumah maupun di luar rumah, misalnya di taman saat terang bulan, atau ditempat lainnya tempat mereka 
sedang bermain. Kawih kaulinan barudak lembur ini bisa dimasukan ke dalam bentuk puisi kakawihan (puisi nyanyian) yaitu sebagai bagian dari cerita rakyat, seperti dikemukakan oleh Yus Rusyana: "Dalam sastra dikenal berbagai bentuk karangan seperti halnya dengan sastra tulisan yaitu bentuk cerita, drama, puisi dan bahasan. Dalam sastra Sunda dikenal cerita rakyat seperti dongeng dan cerita pantun, teater rakyat seperti banjet, topeng, longser, ubrug, dan tarling, puisi rakyat seperti mantra, sawer, pupujian, kakawihan dan paparikan serta bahasan seperti uraian tentang pandangan hidup". Sedangkan sosok kakawihan barudak menurut Dananjaya bisa dimasukan sebagai puisi rakyat, nyanyian rakyat dan permainan rakyat. Hal ini memang bisa dibuktikan bahwa kakawihan barudak mengandung puisi dan lagu serta media untuk mengungkapkannya.

Kakawihan dipandang sebagai puisi rakyat (sajak rakyat) dibagi menjadi tiga kategori yaitu: (a) sajak untuk anak-anak (nursery rhyme); (b) sajak permainan (play rhyme); dan c) sajak untuk menentukan siapa yang "jadi" dalam suatu permainan atau tuduhan (counting out rhyme). Contoh sajak kanak-kanak (nursery rhyme) adalah "Ucang Angge".

Ucang-ucang anggé

Mulung muncang ka paranggé

Digogog ku anjing gedé

Anjing Gedé nu Mang lebé

Ari gog... gog cungungung........."

Menurut Kosasih (2010), kakawihan di atas biasanya dibawakan dalam pola pengasuhan anak, agar anak itu tertawa dan gembira. Si anak akan tertawa dan merasa senang, karena selain diiringi sajak dan lagu, juga ditimang oleh orang tua atau pengasuhnya yang ditempatkan di kedua kaki. Posisinya bisa sambil duduk di golodog atau bisa terlentang, dengan kedua kakinya ditunggangi oleh anak.

Selain kakawihan di atas, banyak contoh kakawihan kaulinan barudak lembur lain yang sudah terdokumentasikan di antaranya:

\section{Oray-orayan}

Oray-orayan,

luar leor mapay sawah

Entong ka sawah, parena keur sedeng beukah

Mending ge teuleum,

di leuwi loba nu mandi

Saha anu mandi, anu mandina pandeuri

\section{Ayang-ayang gung}

Ayang-ayang gung

gung goongna rame

Menak ki Mastanu

Nu jadi wadana

Naha maneh kitu

Tukang olo-olo

Loba anu giruk

Ruket jeung kompeni

Niat naek pangkat

Katon kagorengan

Ngantos Kangjeng Dalem

Lempa lempi lempong

Ngadu pipi jeung nu ompong

Jalan ka Batawi ngemplong

\section{Cingcangkeling}

Cingcangkeling

Manuk cingkleung cindeten

Plos ka kolong

Bapa Satar buleneng

\section{Eundeuk-eundeukan}

Eundeuk-eundeukan lagoni

Meunang peucang sahiji

Leupas deui ku Nini

Beunang deui ku Aki

\section{Jaleuleu}

Jaleuleu ja tulak tujaeman gog

Seureuh leuweung bay Jambe kolot bug Ucing katinggang songsong Ngek ngek! 


\section{Nilai-nilai Sosial dan Nilai-nilai Budaya pada Kakawihan Kaulinan Barudak Lembur}

\section{1) Nilai-nilai Sosial}

Nilai sosial merupakan sikap-sikap dan perasaan yang diterima secara luas oleh masyarakat dan merupakan dasar untuk merumuskan apa yang benar dan apa yang penting. Nilai sosial lahir dari kebutuhan kelompok sosial akan seperangkat ukuran untuk mengendalikan beragam kemauan warganya yang senantiasa berubah dalam berbagai situasi. Dengan ukuran itu masyarakat akan tahu mana yang baik atau buruk, benar atau salah dan boleh atau dilarang.

Nilai sosial adalah nilai-nilai kolektif yang dianut oleh masyarakat kebanyakan. Nilai-nilai sosial merupakan hal yang dituju oleh kehidupan sosial itu sendiri, sedangkan metode pencapaian nilai-nilai sosial tersebut adalah norma, sehingga fungsi norma sosial adalah sebagai petunjuk atau arah tentang cara untuk mencapai nilai (Setiadi dan Kolip, 2011: 124).

Peran nilai sosial adalah sebagai: (1) alat untuk menentukan harga sosial, kelas sosial seseorang; (2) mengarahkan masyarakat untuk berpikir dan bertingkah laku sesuai dengan nilai yang ada; (3) memotivasi manusia untuk berperilaku sesuai dengan yang diharapkan; (4) alat solidaritas atau mendorong masyarakat untuk bekerjasama; dan (5) pengawas, pembatas, pendorong dan penekan individu untuk selalu berbuat baik (Setiadi dan Kolip, 2011: 125).

Pengkajian nilai-nilai sosial yang terdapat dalam kakawihan kaulinan barudak lembur dipaparkan sebagai berikut.

(1) Oray-orayan,

luar leor mapay sawah

Entong ka sawah,

parena keur sedeng beukah

Mending ge teuleum,

di leuwi loba nu mandi

Saha anu mandi, anu mandina pandeuri

Riririri...
Makna yang terkandung dalam kakawihan Oray-orayan di atas mengungkapkan sebuah bentuk permainan seperi ular (oray). Biasanya ular itu hidupnya di sawah, di sungai, atau kali. Walaupun ular dianggap binatang yang menakutkan, namun ular sangat membantu para petani dalam memburu hama tikus di sawah. Kakawihan oray-orayan ini menggambarkan kehidupan ular yaitu luar leor mapay sawah yang artinya bahwa ular jalannya meliuk-liuk mengitari sawah. Kemudian ada sebuah larangan, jangan ke sawah karena sawah sedang penuh dengan padi yang sebentar lagi dipanen (entong $k a$ sawah, paréna keur sedeng beukah). Sebaiknya ke sungai saja, tapi di sungai juga sedang banyak orang yang mandi (mending gé teuleum, di leuwi loba nu mandi). Kemudian terakhir peringatan untuk yang sedang mandi di sungai, jangan mandi sendiri kalau di sungai, harus ada teman karena berbahaya (saha anu mandi, anu mandina pandeuri, riririri...).

Kakawihan ini mengandung nilai-nilai kehidupan yang hendak disampaikan melalui permainan oray-orayan. Nilai-nilai kehidupan ini tampak dari kata-kata atau rumpaka yang disampaikan ataupun melalui gerakan yang mengikutinya. Kakawihan oray-orayan biasanya dinyanyikan anakanak dengan riang gembira sambil berbaris memanjang dan berpegangan pundak dengan kuat supaya tidak terlepas. Kemudian mereka meliuk-liuk menirukan gerakan ular. Kepala ular sebagai pemimpin meliuk-liuk diikuti teman-temannya, kemudian mengejar teman yang menjadi ekor ular untuk menangkapnya dan "jadi" atau kena hukuman.

Nilai-nilai sosial yang tampak pada permainan kakawihan oray-orayan ini diantaranya adalah:

a) nilai kepemimpinan, yaitu kepala ular yang dianggap sebagai pemimpin, harus bisa memimpin dan mengarahkan rakyatnya/bawahannya dengan benar (berperilaku sesuai dengan yang diharapkan); 
b) nilai gotong royong, untuk semua pemain (anak) harus bisa bekerja sama dalam mencapai tujuan bersama (solidaritas);

c) nilai kebersamaan, untuk semua pemain (anak) tidak mementingkan diri sendiri, bermain sesuai aturan yang ada;

d) nilai kepedulian pada orang lain, tidak egois atau ingin senang sendiri;

e) nilai tanggung jawab, kepala ular sebagai penanggungjawab keselamatan rakyatnya;

f) nilai keberanian, berani menghadapi berbagai rintangan.

Nilai-nilai sosial tersebut merupakan sikap-sikap dan perasaan yang diterima secara luas oleh masyarakat Sunda dan merupakan dasar untuk merumuskan apa yang benar dan apa yang penting untuk dilakukan dalam kehidupan bermasyarakat.

(2) Ayang-ayang gung

gung goongna rame

Menak ki Mastanu

Nu jadi wadana

Naha maneh kitu

Tukang olo-olo

Loba anu giruk

Ruket jeung kompeni

Niat naek pangkat

Katon kagorengan

Ngantos Kangjeng Dalem

Lempa lempi lempong

Ngadu pipi jeung nu ompong

Jalan ka Batawi ngemplong

Makna yang terkandung pada kakawihan ayang-ayang gung dapat kita cermati bahwa kakawihan ini bercerita tentang kehidupan pada masa penjajahan Belanda di Indonesia. Terbukti dari katakata kompeni (Belanda), Batawi (Betawi/Jakarta). Kakawihan Ayang-ayang gung menceritakan tentang seorang menak (ningrat/darah biru) dan menjadi wadana (pejabat) bernama $K i$ Mastanu. Jika $K i$ Mastanu datang atau berkunjung ke daerah/desa selalu disambut dengan iringan musik (gung goongna rame). Namun $K i$
Mastanu ini memiliki sifat yang kurang baik (Naha manéh kitu, tukang olo-olo). Bahkan karena sifat yang tidak baiknya itu menimbulkan banyak orang menjadi bermasalah dengan tentara Belanda (loba anu giruk, ruket jeung Kompeni). Ketika $\mathrm{Ki}$ Mastanu menginginkan naik pangkat, orang sudah tahu bahwa dia memiliki sifat atau tujuan yang tidak baik (niat naek pangkat, katon kagorengan). Bahkan demi niatnya itu, dia mendekati pejabat yang lebih tinggi kedudukannya (Ngantos Kanjeng Dalem), tetapi sia-sia harapannya tidak terkabul (lempa lempi lempong, ngadu pipi jeung nu ompong), padahal ada jabatan yang kosong untuk diduduki orang yang tepat sesuai keahliannya (jalan ka Batawi ngemplong).

Ketika melagukan kakawihan ini, biasanya anak-anak melagukannya dengan cara saling memeluk erat pundak teman disampingnya. Seorang diantara mereka menjadi Ki Mastanu berdiri terpisah tidak dipeluk, bahkan ditunjuk-tunjuk oleh kelompok anak yang saling berpelukan tersebut. Berdasarkan gerakan tersebut, kita dapat memaknai bahwa anak-anak yang berpelukan pundak itu adalah rakyat yang selalu bersatu dan memiliki satu tujuan dalam menjalani kehidupan, sedangkan yang seorang yang menjadi Ki Mastanu dipisahkan, karena rakyat tidak menyukai seorang pimpinan yang memiliki sifat tidak terpuji.

Berdasarkan makna kakawihan di atas, maka dapat kita ungkapkan nilai-nilai sosial yang terdapat pada kakawihan tersebut di antaranya yaitu berkaitan dengan kelas-kelas sosial pada masa itu. Sifat-sifat seorang pejabat yang tidak disukai masyarakat, di antaranya:

a) sombong karena memiliki jabatan tinggi;

b) bohong/tidak jujur dalam menjalankan amanah sebagai pejabat;

c) tidak bertanggung jawab dalam menjalankan kewajibannya; dan

d) tidak peduli pada penderitaan orang lain, terutama masyarakat kecil. 
Nilai-nilai sosial yang dimunculkan pada kakawihan Ayang-ayang gung adalah nilai-nilai yang bersifat negatif, tidak boleh dijadikan contoh, namun dijadikan cermin. Sebaliknya dari nilai-nilai tersebut adalah bahwa seorang pejabat atau pemimpin masyarakat harus memiliki sifat: rendah hati, jujur, bertanggung jawab, dan peduli (care) pada orang lain, terutama masyarakat yang dipimpinnya. Itu adalah nilai-nilai yang dianggap baik dan benar oleh masyarakat Sunda menurut kakawihan tersebut.

(3) Jaleuleu ja

Atulak tu ja éman

gog

Seureuh leuweung

bay

Jambé kolot

bug

Ucing katinggang songsong

Ngék!

Zaman dahulu, anak-anak Sunda ketika menyanyikan Jaleuleuja dibagi dua kelompok. Satu kelompok bersembunyi dan kelompok lainnya mencari dan memanggilmanggil dengan teriakan "jaleuleu....", kemudian yang bersembunyi menyahutnya dengan teriakan "Jaa...!" Kemudian diteruskan dengan teriakan Atulak tuja eman...". Dijawab lagi dengan teriakan "gog!", begitu seterusnya sampai bunyi "Ngék"!

Kakawihan ini sangat kental sekali dengan permainan rima atau pengulangan bunyi, baik pengulangan bunyi asonansi maupun aliterasi. Namun dibalik permainan bunyi-bunyi tersebut, terdapat makna yang tersembunyi. Misalnya, apa makna kata jaleuleu ja itu? Menurut beberapa pendapat bahwa kata "jaleuleu ja...atulak tuja eman" merupakan panggilan untuk memberitahukan pada Mang Eman bahwa sudah datang orang Jawa (Ja...). kemudian menyuruh Mang Eman nagog (gog...!) yang artinya jongkok untuk bersembunyi. Selanjutnya, seureuh leuweung (daun sirih dari hutan) dan jambe kolot (buah jambe yang tua) adalah dua jenis tanaman yang biasa digunakan untuk "nyeupah" atau "makan kinang", namun kedua tanaman ini juga bisa dipakai untuk senjata atau tameng. "Jambe kolot, bug...! artinya pohon jambe yang tua dan keras bisa dipakai untuk memukul/menggebug (bug..!). Dipukul sampai seperti seekor kucing yang kesakitan (ucing katinggang songsong, ngek..!).

Nilai-nilai sosial yang dianggap sebagai sebuah norma kehidupan yang terkandung dalam kakawihan Jaleuleu ja adalah:

a) nilai kebersamaan, dengan saling memberikan informasi-informasi penting atau saling mengingatkan jika terjadi hal-hal yang membahayakan;

b) nilai kebermanfaatan alam atau lingkungan atau disebut juga nilai material, yaitu dengan menggunakan seureuh leuweung dan jambe kolot (selain sebagai bahan untuk makan kinang yang dianggap menyehatkan gigi, juga dipakai senjata atau tameng untuk menggebug.memukul);

c) nilai kehati-hatian atau mawas diri dalam menerima tamu atau orang yang tidak dikenal, dengan teriakan jaleuleu...

\section{(4) Trang-trang kolentrang Si Londok paeh nundutan Tikusruk kana durukan Mesat gobang kabuyutan}

Trangtrang kolentrang adalah simbol bunyi-bunyian yang berasal dari suara barang-barang (terbuat dari alumunium, kayu, atau bambu) ketika dipukulkan. Maksud dari suara itu adalah sebagai simbol pemberitahuan kepada masyarakat, seperti halnya yang sering dilakukan penjaga keamanan di kampung-kampung dengan memukul-mukul kentongan ketika ada informasi penting yang akan disampaikan kepada masyarakat. Londok (sejenis binatang reptil seperti bunglon), namun dalam hal ini Londok atau Londo (orang Belanda) yang sering terkantuk-kantuk jika sedang bertugas karena malamnya 
digunakan untuk berpesta, akhirnya tikusruk kana durukan (jatuh/terjerembab ke perapian). Berakhir dengan mesat gobang kabuyutan. Mesat artinya melesat, gobang atau golok, dan kabuyutan/buyut (nenek/kakek moyang). Jadi ketika si Londok terkantuk-kantuk, digunakan oleh kakek/nenek moyang untuk menangkapnya.

Kakawihan ini dilagukan oleh anakanak pada saat bermain sambil memukulmukul bambu atau kayu/kentongan, sambil menyuarakan trangtrang kolentrang...

Nilai-nilai sosial yang dapat kita kaji dari kakawihan trangtrang kolentrang ini adalah nilai-nilai positif dalam kehidupan bermasyarakat atau nilai-nilai yang berkaitan dengan perilaku yang diharapkan, yaitu:

a) nilai kebersamaan, dengan cara memukul secara bersama-sama alat-alat penabuh seperti bambu atau kentongan bambu sebagai simbol informasi (trangtrang kolentrang);

b) nilai kebermanfaatan alam sekitar, yaitu memanfaatkan bambu atau kayu untk dipukul/ditabuh secara bersama-sama sebagai simbol pemberitahuan kepada masyarakat;

c) nilai kepedulian, dengan memberitahukan/mengumumkan sesuatu yang penting kepada orang lain (trangtrang kolentrang);

d) nilai kedisiplinan, dengan cara menentukan strategi yang benar, maka menangkap musuh akan mudah, misalnya pada saat musuh sedang lengah (si londok paéh nuntutan);

e) nilai keberanian, pada saat si londok paeh nuntutan, maka dengan berani mesat gobang kabuyutan (menangkap atau membunuh musuh).

\section{(5) Eundeuk-eundeukan lagondi Meunang peucang sahiji \\ Leupas deui ku Nini Beunang deui ku Aki}

Kakawihan eundeuk-eundeukan ini biasa dinyanyikan anak-anak sambil naik ke pohon buah (misalnya: pohon jambu, pohon mangga, atau pohon belimbing). Sambil mendendangkan kakawihan ini mereka menggoyang-goyangkan dahan pohon yang dinaikinya dengan harapan buah itu akan berjatuhan. Jika buah itu belum berjatuhan mereka akan terus mengulang-ulanginya sampai apa yang mereka inginkan (buah berjatuhan) terlaksana. Eundeuk-eundeukan lagondi artinya menggoyang-goyangkan pohon. Meunang peucang sahiji, secara harfiah berarti 'mendapat rusa satu'. Namun jika dikaitkan dengan baris sebelumnya bisa saja bukan rusa, tetapi sesuatu yang dincarnya. Namun sayang ketika yang diincarnya itu sudah didapatinya, malah lepas lagi karena ulah neneknya (leupas deui ku nini). Tapi akhirnya dapat ditangkap lagi oleh si kakek (beunang deui ku aki).

Jika kita kaji berdasarkan makna yang terkandung dalam baris-baris kata dan permainan yang dilakukan anak-anak dalam mengawihkan eundeuk-eundeukan itu, maka dapat kita temukan nilai-nilai sosial yang terdapat didalamnya yaitu:

a) nilai keberanian, dengan cara naik ke atas pohon sambil menggoyanggoyangkan dahan yang dinaikinya, hal itu menunjukkan bahwa anak-anak memiliki keberanian/tidak takut jatuh;

b) nilai tidak putus asa atau tidak cepat menyerah, merupakan nilai positif yang harus dimiliki anak-anak dengan cara terus-terusan mengoyang-goyangkan dahan dan menyanyikan kawih ini sampai buah yang diinginkannya berjatuhan;

c) nilai bangga dengan nenek dan kakeknya yang mau bekerja sama dalam menangkap rusa, turut serta dinyanyikan dalam kakawihan ini.

\section{2) Nilai-nilai Budaya}

Nilai budaya merupakan konsep abstrak mengenai masalah dasar dan bersifat umum. Nilai budaya ini sangat penting serta bernilai bagi kehidupan masyarakat. Nilai budaya menjadi acuan tingkah laku sebagian besar anggota 
masyarakat yang bersangkutan, berada dalam alam pikiran mereka dan sulit diterangkan secara rasional. Nilai budaya bersifat langgeng, tidak mudah berubah atau diganti dengan nilai budaya lain. Anggota masyarakat memiliki nilai sebagai hasil proses belajar sejak masa kana-kanak sampai dewasa hingga mendarah daging. Nilai-nilai budaya merupakan nilai- nilai yang disepakati dan tertanam dalam suatu masyarakat, lingkup organisasi, lingkungan masyarakat, yang mengakar pada suatu kebiasaan, kepercayaan (believe), simbolsimbol, dengan karakteristik tertentu yang dapat dibedakan satu dan lainnya sebagai acuan prilaku dan tanggapan atas apa yang akan terjadi atau sedang terjadi. Nilai budaya menjadi pedoman tingkah laku dalam kehidupan bermasyarakat, misalnya: tolong menolong, bergotong royong, bermusyawarah, setia kawan, harga diri, tertib, dan lain-lain yang tercermin dalam berbagai aktivitas hidup (Setiadi, 2011: 127).

Pengkajian nilai-nilai budaya yang terdapat dalam kakawihan kaulinan barudak lembur dipaparkan sebagai berikut.

(1) Pada kakawihan oray-orayan, nilai-nilai budaya yang dapat kita pelajari adalah:

a) bahwa nilai budaya masyarakat Sunda yang berkaitan antara manusia dengan alam adalah harus bisa menyelaraskan diri dengan alam, tidak boleh mengotori atau merusak alam (oray-orayan, luar leor mapay sawah, entong ka sawah, parena keur sedeng beukah, mending ge teuleum...);

b) hubungan manusia dengan sesama harus dijalani dengan baik dan dengan cara yang baik pula (mending ge teuleum di leuwi loba nu mandi);

c) menjalani hidup pun harus waspada/hati-hati supaya tidak mudah terbawa arus yang salah (saha anu mandi, anu mandina pandeuri...).
(2) Pada kakawihan ayang-ayang gung ini, nilai-nilai budaya masyarakat Sunda yang berkaitan dengan hakikat kehidupan, yaitu bahwa:

a) sombong merupakan sifat yang tidak disukai oleh masyarakat Sunda (naha maneh kitu, tukang olo-olo);

b) tidak jujur atau tidak amanah dalam melaksanakan tugasnya sebagai seorang pejabat pemerintah atau pemimpin merupakan hal yang tidak terpuji (niat naek pangkat, katon kagorengan);

c) tidak bertanggung jawab dalam menjalankan pekerjaannya sehingga membuat keributan/ kekisruhan, juga tidak disukai masyarakat Sunda (loba anu giruk);

d) senang mengadu domba yang mengakibatkan orang lain berkelahi/bermusuhan merupakan cara yang sangat tidak terpuji (ruket jeung kompeni);

e) mencari kedudukan atau jabatan dengan jalan atau cara yang tidak jujur merupakan hal yang salah (niat naek pangkat, katon kagorengan). Hubungan manusia dengan manusia lain harus dilakukan dengan baik, tetapi tidak dengan cara-cara yang curang/licik.

(3) Nilai-nilai budaya yang berkaitan dengan hakikat kehidupan yang tercantum pada kakawihan jaleuleu ja yaitu:

a) masyarakat Sunda menghormati kebersamaan sesama suku Sunda, diantaranya ketika ada informasiinformasi penting maka segera disampaikan (atulak tuja eman...);

b) berkaitan dengan hubungan antara manusia dengan alam sekitar yaitu, bahwa masyarakat Sunda pun selalu berupaya memanfaatkan alam dan lingkungan sekitar untuk memenuhi kebutuhan hidupnya (seureuh leuweung..., jambe kolot...);

c) sikap berhati-hati dan mawas diri pun harus selalu diterapkan dalam 
kehidupan sehari-hari supaya terhindar dari hal-hal yang membahayakan dirinya (atulak tuja eman...gog!).

Berdasarkan nilai-nilai budaya tersebut melahirkan nilai-nilai karakter yang melekat pada masyarakat Sunda sesuai dengan kakawihan ini yaitu: mendahulukan kepentingan umum daripada kepentingan dirinya, efektif dan efisiensi dalam menggunakan alam sekitar, dan selalu berhati-hati atau mawas diri.

(4) Pada kakawihan trang trang kolentrang ,nilai-nilai budaya yang berkaitan dengan kehidupan masyarakat Sunda adalah:

a) masyarakat Sunda memiliki kebiasaan, jika melakukan suatu pekerjaan akan memilih dikerjakan secara bersama-sama atau bergotong royong supaya terasa mudah, ringan, dan cepat;

b) masyarakat Sunda pun tidak akan berdiam diri ketika mengetahui ada sesuatu yang harus disampaikan kepada masyarakat, maka akan segera menyampaikannya (trang trang kolentrang);

c) dengan kedisiplinan dan strategi yang baik, maka akan mudah mengerjakan suatu pekerjaan (mesat gobang kabuyutan).

(5) Nilai-nilai budaya yang berkaitan dengan acuan perilaku yang harus diikuti yang terdapat pada kakawihan eundeuk-eundeukkan, yaitu:

a) keberanian untuk naik, tidak takut ketinggian, berani menempuh bahaya jatuh, diwariskan orang tua pada anak-anaknya, dapat kita temukan pada kakawihan ini;

b) tidak mengenal putus asa atau cepat menyerah dalam memperoleh citacita atau keinginannya, merupakan hal yang harus terus dipertahankan;

c) bangga dengan orang tuanya, keluarganya, merupakan nilai nasionalisme yang harus dipertahankan;

d) bekerja sama dalam melakukan pekerjaan harus terus dilakukan karena dengan bekerja sama, sebuah pekerjaan akan cepat selesai dan hasilnya akan lebih baik.

\section{Etnopedagogi}

Etnopedagogik adalah praktek pendidikan berbasis kearifan lokal dalam berbagai ranah seperti pengobatan, seni bela diri, lingkungan hidup, pertanian, ekonomi, pemerintahan, sistem penanggalan, dan lain-lain. Etnopedagodik memandang pengetahuan atau kearifan lokal sebagai sumber inovasi dan keterampilan yang dapat diberdayakan demi kesejahteraan masyarakat. Kearifan lokal adalah koleksi fakta, konsep kepercayaan, dan persepsi masyarakat ihwal dunia sekitar, menyelesaikan masalah, dan memvalidasi informasi. singkatnya, kearifan lokal adalah bagaimana pengetahuan dihasilkan, disimpan, diterapkan, dikelola, dan diwariskan (Alwasilah, 2009: 50).

Berdasarkan pemahaman di atas, maka kajian secara etnopedagogik pada kakawihan barudak lembur merupakan sebuah langkah untuk melestarikan dan memberdayakan hasil budaya Sunda untuk kesejahteraan masyarakat. Fakta-fakta, konsep kepercayaan, persepsi masyarakat Sunda tentang dunia sekitar, dan cara masyarakat Sunda dalam menyelesaikan masalah, dapat digali melalui kakawihan barudak lembur ini.

Pendidikan sebagai lembaga pewaris dan penerus kebudayaan, sudah semestinya bertumpu pada realitas bahwa ruang dunia ini ini beraneka ragam dan berbeda-beda. Menurut Sumardjo (2011:274), kita dididik untuk dapat hidup di lingkungan budaya kita dan sedapat mungkin menyumbangkan sesuatu demi kelangsungan hidup bersama kita. Orientasi pendidikan bukan hanya kehidupan masa depan, tetapi juga orientasi masa kini sebagai akibat dari tekad, ucap, dan lampah generasi-generasi sebelum kita. 
Itulah kearifan sangkan paran (Sunda), darimana kita berasal dan kemana kita menuju.

Pendidikan modern kita selama ini adalah sebuah diskontinuitas, ketidak sinambungan dengan sejarah asal-usul serta kondisi dan situasi kontemporernya. Tidak disadari kita tercerabut dari akar-akar budaya lingkungan sendiri, baik lokal maupun nasional. Pendidikan kita justru mencangkokan diri dengan akar-akar budaya bangsa lain yang kita kagumi (Sumardjo, 2011: 275).

Etnopedagogi kembali membangun kontinuitas masa lampau dan masa kini di lokal dan etnis tertentu di Indonesia, dan hasilnya adalah untuk kesejahteraan nasional.

Persoalan etnopedagogi yang utama adalah perbedaan diametral antara kebudayaan pramodern lokal dengan kebudayaan modern nasional (Sumardjo, 2011: 277). Perbedaan ini begitu tajam seperti perbedaan budaya Yunani Homeros (mitos) dan Yunani Sokrates (logos, antoposentris), dan perbedaan budaya abad pertengahan Eropa yang agamawi dengan Pencerahan yang akal budi. Cara Eropa mengatasi perbedaan ini adalah meninggalkan sama sekali yang mitos untuk memenangkan logos.

Ternyata cara Eropa berbeda dengan cara Jepang dan Cina. Jepang dan Cina menggandeng budaya mitos dan budaya logos dalam dunia modern ini. Perbedaan Eropa dan Asia ini didasari oleh perbedaan filosofi dan menghasilkan sistem logika yang berbeda. Logika Barat Aristotelian mengenal empat prinsip logika, yaitu prinsip identitas, prinsip kontradiksi, prinsip menolak kemungkinan ketiga, dan prinsip penjelasan yang secukupnya. Prinsip ini berbeda dengan logika Timur yang menerima adanya kemungkinan ketiga dari suatu kontradiksi, yakni harmoni kebenaran (Sumardjo, 2011: 278). Etnopedagogi berpihak pada logika timur yang sukses dijalankan Jepang, Cina, korea, Muangthai, yaitu berlandaskan logika non-Aristotelian. Contoh di Indonesia adalah Bali.

Filosofi masyarakat dan budaya Sunda adalah yang dikenal dengan istilah tritangtu, yakni tekad, ucap, lampah (silih asih, silih asah, silih asuh). Tekad yaitu kehendak, keinginan, niat, cita-cita. Ucap adalah perkataan dan lampah adalah perbuatan, kekuatan, tenaga. Ketiga hal ini harus saling melengkapi dan saling menyempurnakan demi kepentingan bersama. Menurut Sumardjo (2011: 280), filosofi tritangtu ini harus digali lebih mendalam sehingga dapat diacu sebagai pegangan kearifan lokal dengan tingkat kepastian yang tinggi. Syarat etnopedagogi dalam hal ini yakni kembali ke akar budaya lokal sehingga pendidikan merupakan sebuah kontinuitas kebudayaan. Kajian etnopedagogi pada kakawihan barudak lembur merupakan langkah awal memahami kembali kehidupan sosial dan budaya Sunda masa lampau untuk membangun kontinuitas masa lampau dan masa kini di lokal dan etnis tertentu di Indonesia, dan hasilnya adalah untuk kesejahteraan nasional.

\section{Pendidikan Multikultural}

Indonesia merupakan negara dengan latar belakang budaya, suku, bahasa, dan agama yang sangat majemuk, Indonesia memerlukan pendekatan dan instrumen strategik yang dapat dijadikan sebagai sebuah gerakan nasional untuk mewujudkan persatuan, kesatuan, dan keutuhan bangsa agar menjadi bangsa yang berdaulat dan bermartabat. Salah satu instrumen pendekatannya adalah melalui pendidikan multikultural.

Pendidikan multikultural merupakan suatu pendekatan progresif untuk melakukan transformasi pendidikan yang secara holistik memberikan kritik dan menunjukkan kelemahan-kelemahan, kegagalan-kegagalan dan diskriminasi di dunia pendidikan. Pendidikan multikultural sebagai instrumen rekayasa sosial mendorong sekolah supaya dapat berperan dalam menanamkan kesadaran dalam 
masyarakat multikultur dan mengembangkan sikap tenggang rasa dan toleran utuk mewujudkan kebutuhan serta kemampuan bekerjasama dengan segala perbedaan yang ada (Zamroni, 2011: 144).

Secara generik, pendidikan multikultural memang sebuah konsep yang dibuat dengan tujuan untuk menciptakan persamaan peluang pendidikan bagi semua siswa yang berbeda-beda ras, etnis, kelas sosial dan kelompok budaya. Salah satu tujuan penting dari konsep pendidikan multikultural adalah untuk membantu semua siswa agar memperoleh pengetahuan, sikap dan keterampilan yang diperlukan dalam menjalankan peran-peran seefektif mungkin pada masyarakat demokrasipluralistik serta diperlukan untuk berinteraksi, negosiasi, dan komunikasi dengan warga dari kelompok beragam agar tercipta sebuah tatanan masyarakat bermoral yang berjalan untuk kebaikan bersama (Ruslan, 2008).

Pendidikan multikultural mencerminkan keseimbangan antara pemahaman persamaan dan perbedaan budaya yang mendorong individu untuk mempertahankan dan memperluas wawasan budaya dan kebudayaan mereka sendiri.

Pengimplementasian hasil kajian etnopedagogi terhadap kakawihan kaulinan barudak lembur dalam pendidikan multikultural adalah salah satu upaya penyadaran individu (peserta didik) di dalam mempertahankan dan memperluas warisan budaya mereka yang sudah mulai terlupakan. Pelaksanaan pendidikan multikultural ini memandang kakawihan barudak lembur sebagai sebuah kearifan lokal juga sebagai sumber inovasi dan keterampilan yang dapat diberdayakan.

Fakta-fakta, konsep kepercayaan, persepsi masyarakat Sunda tentang dunia sekitar, dan cara masyarakat Sunda dalam menyelesaikan masalah, dapat digali melalui kakawihan barudak lembur ini.

\section{SIMPULAN}

Berdasarkan paparan di atas, maka penulis dapat menarik beberapa simpulan sebagai berikut.

1) Nilai-nilai sosial dan budaya pada kakawihan kaulinan barudak lembur merupakan materi yang cocok dan aplikatif pada pembelajaran bahasa dan sastra Indonesia untuk pengembangan nilai-nilai multikultur yang bersumber pada kearifan lokal masyarakat Indonesia, khususnya Sunda.

2) Penerapan pembelajaran bahasa dan sastra Indonesia yang berbasis multikultur menjadi sebuah kebutuhan bangsa Indonesia yang beraneka ragam etnis dan budayanya.

\section{PUSTAKA RUJUKAN}

Alwasilah, A. C, dkk. (2009). Etnopedagogi (Landasan Praktek Pendidikan dan Pendidikan Guru). Bandung: Kiblat

Danandjaja, J. (1991). Folklor Indonesia (Ilmu Gosip, Dongeng, dan lain-lain). Jakarta: PT Pustaka Utama Grafiti.

Depdiknas. (2003). Undang-Undang No. 20

Tahun 2003 tentang Sistem Pendidikan Nasional

Kosasih, D. (2010). Etnopedagogi dalam Kaulinan dan Kakawihan Barudak Sunda (makalah). Yogyakarta.

Risal, M. (2011). Implementasi Pendidikan Multikultural dalam Dunia Pendidikan.

Ruslan Ibrahim. (2008). Pendidikan Multikultural: Upaya Meminimalisir Konflik dalam Era Pluralitas Agama.

Setiadi, E.M dan Kolip, U. (2011). Pengantar Sosiologi. Jakarta: Prenada Media Group.

Sims, Martha C. (2005). Living Folklore (An Introduction ti the Study of People and Their Traditions). Logan, Utah: Utah State University Press

Sumardjo, J. (2011). Sunda (Pola Rasionalitas Budaya). Bandung: Kelir

Zamroni. (2011). Pendidikan Demokrasi pada Masyarakat Multikultural. Yogyakarta: Gavin Kalam Utama. 
208| LOKABASA Vol. 4, No. 2, Oktober 2013

\section{UCAPAN TERIMA KASIH}

Ucapan terima kasih dan penghargaan setinggi-tingginya saya sampaikan kepada semua pihak yang telah membantu penelitian ini. Tidak lupa pula penulis mengucapkan terima kasih kepada Penyunting Jurnal Lokabasa yang sudah berkenan memuat tulisan ini. 